\title{
Permanent Bilateral Carotid Filters for Stroke Prevention in Atrial Fibrillation
}

\author{
Tom De Potter ${ }^{1}$ (D) Ofer Yodfat $^{2} \cdot$ Guy Shinar $^{2} \cdot$ Avraham Neta $^{2} \cdot$ Vivek Y. Reddy $^{3} \cdot$ Petr Neuzil $^{4}$. \\ Roland Veltkamp ${ }^{5,6,7} \cdot$ Stuart J. Connolly ${ }^{8}$
}

Published online: 10 September 2020

(C) The Author(s) 2020

\begin{abstract}
Purpose of Review A novel permanent carotid filter device for percutaneous implantation was developed for the purpose of stroke prevention. In this review, we cover rationale, existing preclinical and clinical data, and potential future directions for research using such a device.

Recent Findings The Vine ${ }^{\mathrm{TM}}$ filter was assessed for safety in sheep and in 2 observational human studies, the completed CAPTURE $1(n=25)$ and the ongoing CAPTURE 2 (planned $n=100)$. CAPTURE 1 has shown high procedural and longterm implant safety. A control group was not available for comparison.

Summary A mechanical filter for permanent stroke prevention can be implanted bilaterally in the common carotid artery safely and efficiently. A randomized trial is planned for $2021(n=3500$, INTERCEPT $)$ to demonstrate superiority of a filter + anticoagulation strategy over anticoagulation alone in patients at high risk for ischemic stroke.
\end{abstract}

Keywords Atrial fibrillation $\cdot$ Carotid filter $\cdot$ Common carotid artery $\cdot$ Embolic protection $\cdot$ Stroke prevention

This article is part of the Topical Collection on Invasive Electrophysiology and Pacing

Tom De Potter

tom.de.potter@olvz-aalst.be

Ofer Yodfat

ofer@t-tanium.com

Guy Shinar

shinarg@gmail.com

Avraham Neta

avi@javelinmed.com

Vivek Y. Reddy

vivek.reddy@mountsinai.org

Petr Neuzil

petr.neuzil@homolka.cz

Roland Veltkamp

roland.veltkamp@krupp-krankenhaus.de

Stuart J. Connolly

Stuart.Connolly@phri.ca
1 Cardiovascular Center, OLV Hospital, Moorselbaan 164, B-9300 Aalst, Belgium

2 Javelin Medical Ltd., Yokne'am, Israel

3 Helmsley Electrophysiology Center, Division of Cardiology, Icahn School of Medicine at Mount Sinai, New York, NY, USA

4 Department of Cardiology, Homolka Hospital, Prague, Czech Republic

5 Department of Brain Science, Imperial College London, London, UK

6 Department of Neurology, Alfried Krupp Krankenhaus, Essen, Germany

7 Department of Neurology, University Heidelberg, Heidelberg, Germany

8 Population Health Research Institute, McMaster University, Hamilton, Ontario, Canada 


\section{Abbreviations}

AF Atrial fibrillation

CCA Common carotid artery

OAC Oral anticoagulants

NOAC New oral anticoagulants

\section{Introduction}

Stroke prevention in atrial fibrillation (AF) patients is an important medical need with major consequences if left unmet. In the USA, AF prevalence is $>6$ million, with an incidence of 1.2 million cases per year $[1,2]$. Nearly 800,000 Americans suffer from stroke each year, and one out of three is associated with $\mathrm{AF}$ (67\% of them with prior AF) [3].

Stroke risk in AF patients is commonly estimated using the $\mathrm{CHA}_{2} \mathrm{DS}_{2}$-VASc scoring system [4]. In AF patients not taking oral anticoagulants $(\mathrm{OAC})$, the average annual stroke risk is $\sim 5 \% /$ year $\left(2 \%\right.$ and $11 \%$ in $\mathrm{CHA}_{2} \mathrm{DS}_{2}-\mathrm{VASc}=2$ and 9 , respectively) [5-8]. Warfarin and new oral anticoagulants (NOAC) reduce the stroke risk in AF patients by at least $65 \%$ [9]. However, in some high-risk groups of AF patients, the annual ischemic stroke risks remain high even when receiving OAC, with estimates of $8.9 \%$ (first year after recent stroke while on $\mathrm{OAC}$ ) [10•], 5.6\% (after recent stroke and age $>75$ ) [11], 4.4\% (within 90 days of stroke) [12], 2.3-3.2\% (with any remote history of stroke ( $>90$ days)) [13-15], and $1.8 \%$ (age > 75) [16].

One of the reasons that stroke risk can remain high in some $\mathrm{AF}$ patients is that long-term adherence to OAC treatment is sub-optimal. The rate of temporary OAC discontinuation over 3 days was $63 \%$ in the ENGAGE AF-TIMI 48 randomized controlled trial (edoxaban vs. warfarin) [17]. In a retrospective cohort analysis of a large US commercial insurance database, fewer than half (47.5\%) of the patients had $\geq 80 \%$ days covered by NOAC [18]. The resulting stroke risk during interruption and discontinuation was substantially increased. In the ROCKET AF trial (rivaroxaban vs. warfarin), stroke risks during rivaroxaban temporary interruptions (3-30 days) and permanent discontinuations ( $>30$ days) were $6.2 \% /$ year and $25.6 \% / y e a r$, respectively [19].

There is substantial necropsy evidence demonstrating that total anterior stroke only occurs if the proximal stem (M1) of the middle cerebral artery (MCA) is occluded [20]. Partial anterior stroke consists of more restricted cortical infarcts due to occlusion of the upper or lower divisions (M2) of the MCA [21]. The underlying cause of these strokes, in most cases, is a proximally originating embolus rather than in situ thrombosis. Thus, in AF patients, anterior circulation strokes ( $\sim 80 \%$ of strokes) are likely attributable to emboli originating from central circulatory system. Anterior circulation strokes are more severe than lacunar strokes and posterior circulation strokes [22]. Compared with lacunar stroke, the odds ratios of death for total anterior circulation stroke, partial anterior circulation stroke, and posterior circulation stroke are 5.73, 1.65, and 2.22 , respectively, and the odds ratios of disability are $3.27,1.73$, and 0.88 , respectively. Thus, protection against anterior circulation strokes in $\mathrm{AF}$ patients is a major priority, compared with strokes in other distributions.

The calibers (diameters) of the middle cerebral and anterior cerebral arteries and their first branches are $>1.5 \mathrm{~mm}$ [23-28]. Thus, a permanent, bilateral, common carotid artery (CCA) filter that can exclude emboli of $>1.5 \mathrm{~mm}$ in size could therefore potentially reduce the risk of most major anterior circulation embolic strokes.

Accordingly, a CCA filter device has been designed to be a permanent implant inserted into the common carotid artery to capture emboli $>1.5 \mathrm{~mm}$ in size and thus prevent their propagation to the brain (Fig. 1). In AF patients, it is designed to prevent emboli from reaching the anterior cerebral circulation and thus to prevent most anterior circulation strokes (representing about $80 \%$ of stroke in AF patients). The implant is being developed as a means of providing permanent stroke prevention in AF patients at high stroke risk, despite ongoing treatment with $\mathrm{OAC}$.

\section{Device Description}

The Vine ${ }^{\mathrm{TM}}$ Embolic Protection System ("system," Fig. 2) consists of the Vine ${ }^{\mathrm{TM}}$ CCA Filter ("implant") and a Vine ${ }^{\mathrm{TM}}$ Inserter (inserter).

The implant is made of a super-elastic single nitinol wirea monofilament structure capable of assuming a substantially linear shape in the un-deployed state, and a functional shape, once deployed. In the deployed state, the implant (Fig. 3) comprises a helix that resides within the CCA lumen and a linear stem that traverses the CCA wall. The helix includes 3 segments: supporting coils, filtering portion ("filter"), and leading coils. The filtering portion has a cone shape facing upstream (toward the heart) and includes coils that are spaced approximately $0.85 \mathrm{~mm}$ apart. During deployment, the implant is fixed in place by anchors (internal and external). The implant is provided in 10 sizes $(5.5-10 \mathrm{~mm}$, at $0.5-\mathrm{mm}$ intervals) to accommodate CCA diameters of $4.8-9.8 \mathrm{~mm}$. In terms of anatomy, extreme tortuosity (at the discretion of the implanting physician) or reverse tapering (an increasing diameter cranially) would present a contra-indication to implantation. The implant may be retrieved without surgery using a pulling wire that is connected to the stem. At up to 4 hours, the pulling wire is cut at the skin level after which surgery would be required for removal.

The implant is deployed through the needle of an inserter under ultrasound imaging guidance (Fig. 4). The inserter is comprised of a Needle Unit and a Motor Unit (Fig. 2). The Needle Unit includes a siliconized insertion needle with a flag 
Fig. 1 Typical implant position in the common carotid artery. Illustration shows potential captured thrombus location (red circle)

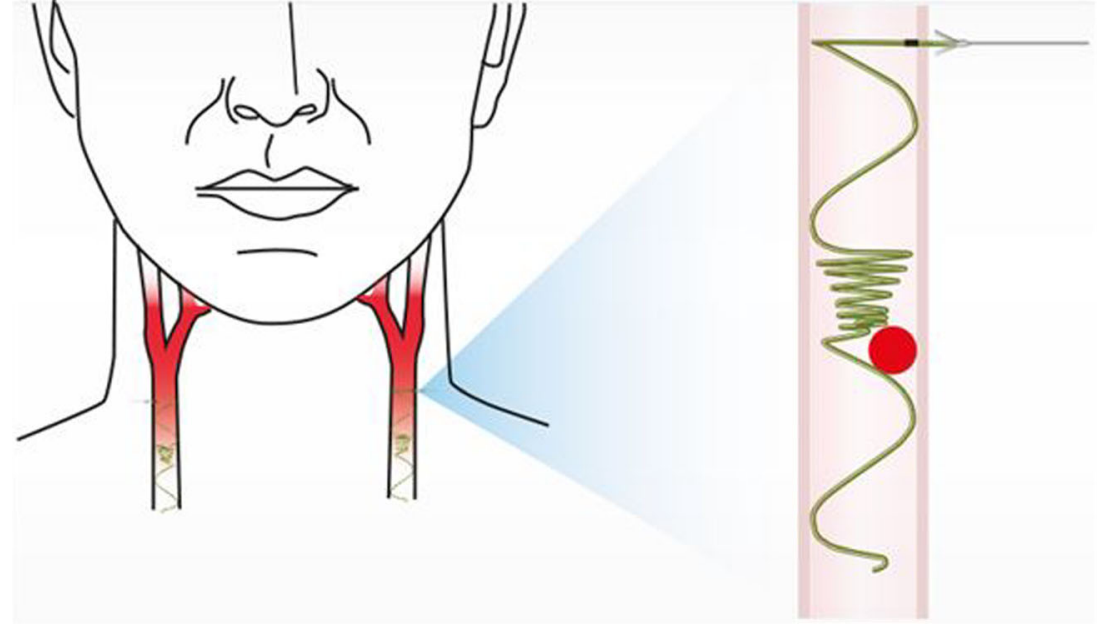

indicating the needle bevel orientation and a plunger. The Motor Unit includes motor, gear, hardware, and software. Once the Motor Unit and the Needle Unit are connected, upon pressing the operating button, the motor and gear automatically drive the plunger that pushes the implant out of the needle.

\section{Preclinical Studies}

\section{In vitro Flow Simulator Testing}

The implant's ability to capture potential emboli was evaluated in a pulsatile flow simulator which mimics human CCA blood flow- an accepted method to evaluate the performance of filtration devices [29-30]. A pulsatile pump was used to circulate a blood simulation (37\% glycerol in water) within a silicone tube at time-varying flow rates, representative of the human CCA diameter and flow [31]. Nylon balls (round, firm, symmetric balls of fixed size of $1.2 \mathrm{~mm}$ ) and polyvinyl alcohol flakes (designed to mimic the consistency of blood clot texture and shape, at size ranges of $1.2-1.4 \mathrm{~mm}$ and $1.4-1.6 \mathrm{~mm}$ ) were individually $(n=30)$ released into the flow, and capture performance of implants was tested. In the flow simulator, the implant captured $100 \%$ of nylon balls at fixed size of $1.2 \mathrm{~mm}$. For polyvinyl alcohol particles in two size ranges of $1.2-1.4 \mathrm{~mm}$ and 1.4 $1.6 \mathrm{~mm}$, capture efficiency was $92 \%$ and $100 \%$, respectively.

\section{In vitro Captured Thromboemboli Integrity}

Sheep blood was placed in silicone tubes of $3.0 \mathrm{~mm}$ diameter. After 2 days, the tubes were cut and clots were extracted. Using the flow simulator described above, these clots $(n=100)$ at 3-7 $\mathrm{mm}$ in length were injected into the manifold and their integrity was observed during capture by the implant. All (100\%) of the captured emboli were firmly adhered to the filtering portion of the implant, and no $(0 \%)$ embolus breakdown was observed (embolus was progressively dissolved, and no distal pieces were observed in the manifold).

\section{In vivo Sheep Animal Model Testing}

Sheep were used for in vivo testing of the Vine ${ }^{\mathrm{TM}}$ system because sheep have high rates of implant thrombogenicity including hypercoagulability, reduced clot lysis, and lack of response to aspirin [32-36]. The following parameters were assessed in acute and chronic studies: procedural success, implant safety, retrieval with pulling wire, surgical removal, fate of captured emboli, and inserter handling and performance characteristics. Safety parameters were assessed by ultrasound and X-ray at follow-up and by histopathology and scanning electron microscope (SEM) at termination.
Fig. 2 The Vine ${ }^{\mathrm{TM}}$ Embolic Protection System

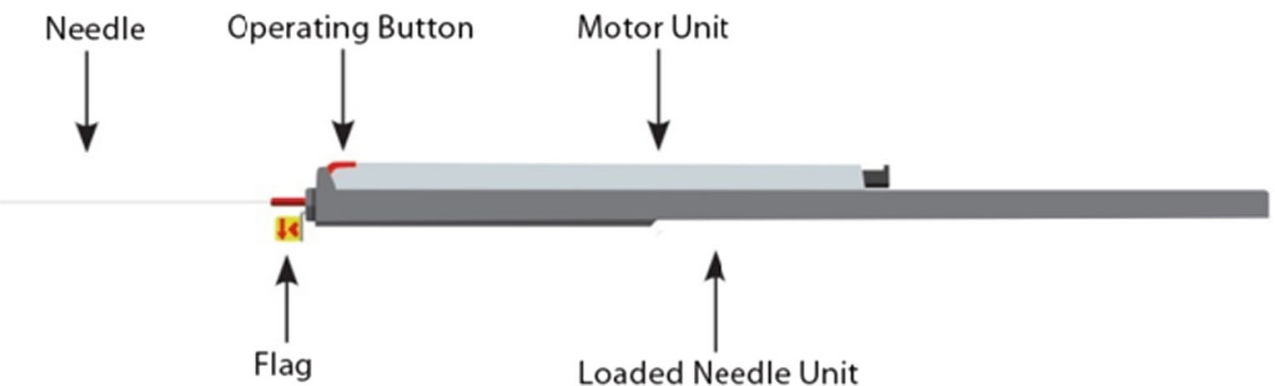


Fig. 3 The implant: longitudinal (a) and cross section (b) views a

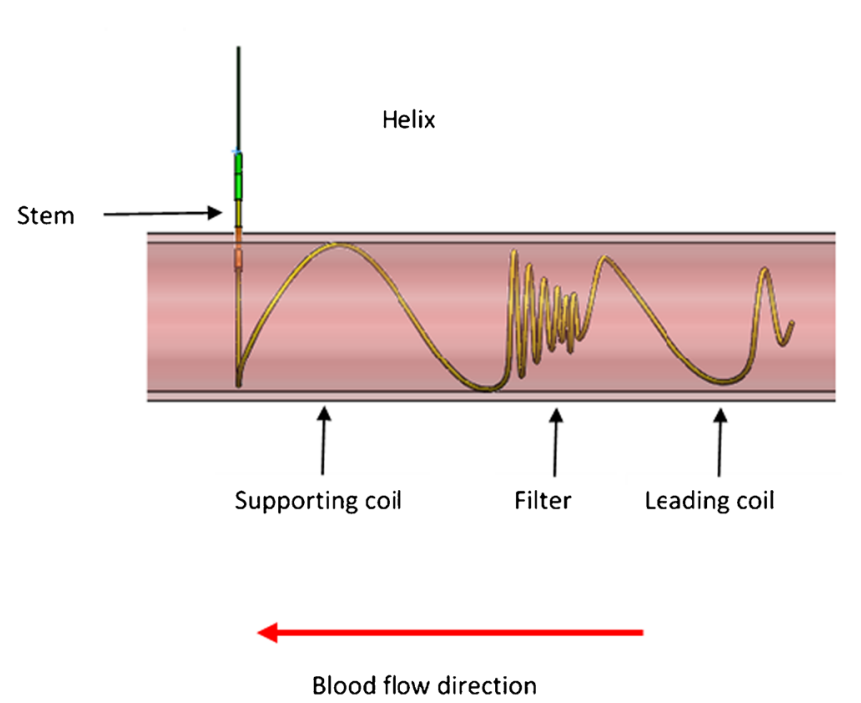

lood flow direction b

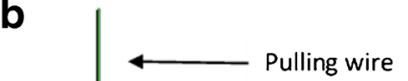

\section{Procedural and Implant Safety Studies}

Sheep $(n=30)$ were selected based on their CCA diameter $(\mathrm{mm})$. For each sheep, one implant was deployed under ultrasound imaging guidance in each CCA, using the inserter. Enoxaparin was administrated on implantation day and for 2 more days post implantation together with clopidogrel. After implantation, CCA ultrasound examination was conducted at follow-ups at 4, 12, 13, 23, and 31 weeks, while the sheep were awake. At termination, ultrasound (before and after anesthesia) and X-ray examinations were performed. All implantation sites were harvested before the animals were euthanized, and the samples were sent for histopathology and SEM analysis.

Overall, 30 of 30 animals (100\%) survived and were in good health until sacrifice at the termination of the study. There were 64 implant deployments, of which 60 were successfully positioned. Procedural safety (lack of major bleeding, thrombus on implant, CCA damage or occlusion, and proper position of implant) was 64/64 (100\%), and implantation success (proper implant position with a maximum of one implant retraction) was 60/60 (100\%). In 4 cases of initial improper implant position, the implant was retrieved and successfully redeployed during the procedure. Representative images of the implant on ultrasound and Xray are shown in Fig. 5.

In histopathology analysis, no macroscopic abnormalities were observed at the implanted sites surrounding tissues and distant organs (lungs, liver, kidneys, spleen, heart, brain). The implants were correctly deployed and secured at the implantation sites in all specimens analyzed at 4 (10/10 implants), 12 (10/10), 13 (10/10), 23 (10/10), and 31 weeks (10/10). In two specimens (observed at 23 and 31 weeks), recent thrombi of sub-millimetric thickness were observed; occurrence of these thrombi was possibly related to pre-sacrifice/sacrifice procedure. There was no neo-intimal growth on the filtering portion wire. In some cases, there was partial neo-intimal growth on portions of the leading and supporting coils. Representative histopathology images are shown in Fig. 6. Black dots represent implant wire cross sections. Also note that the artery wall
Fig. 4 Implantation procedure positioning

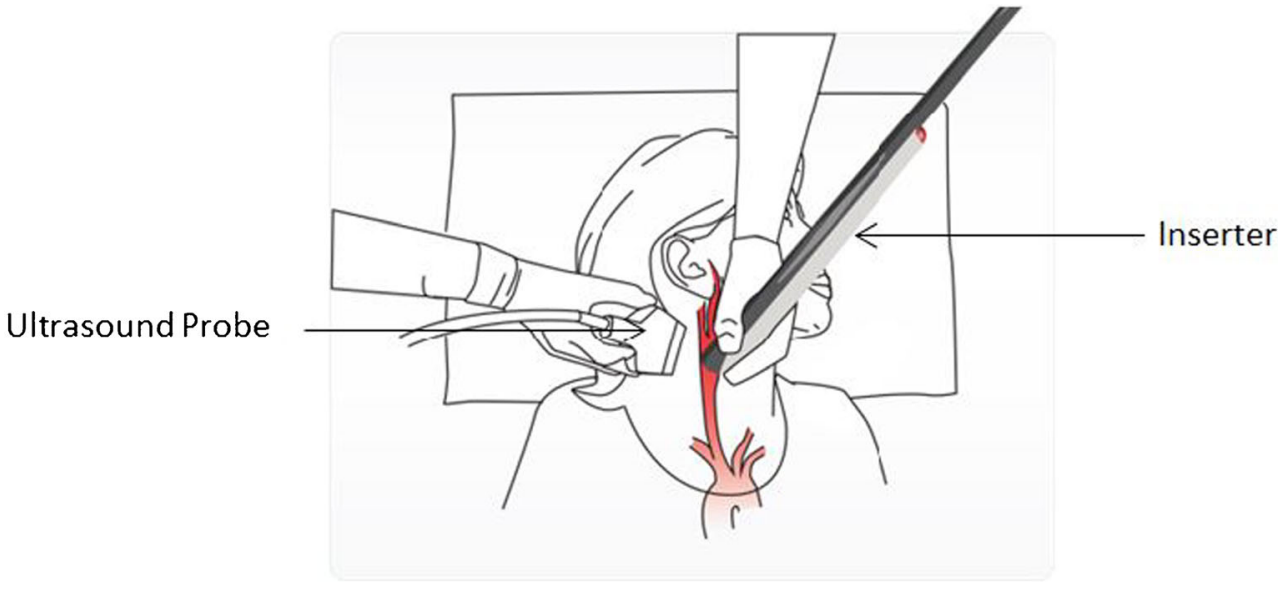



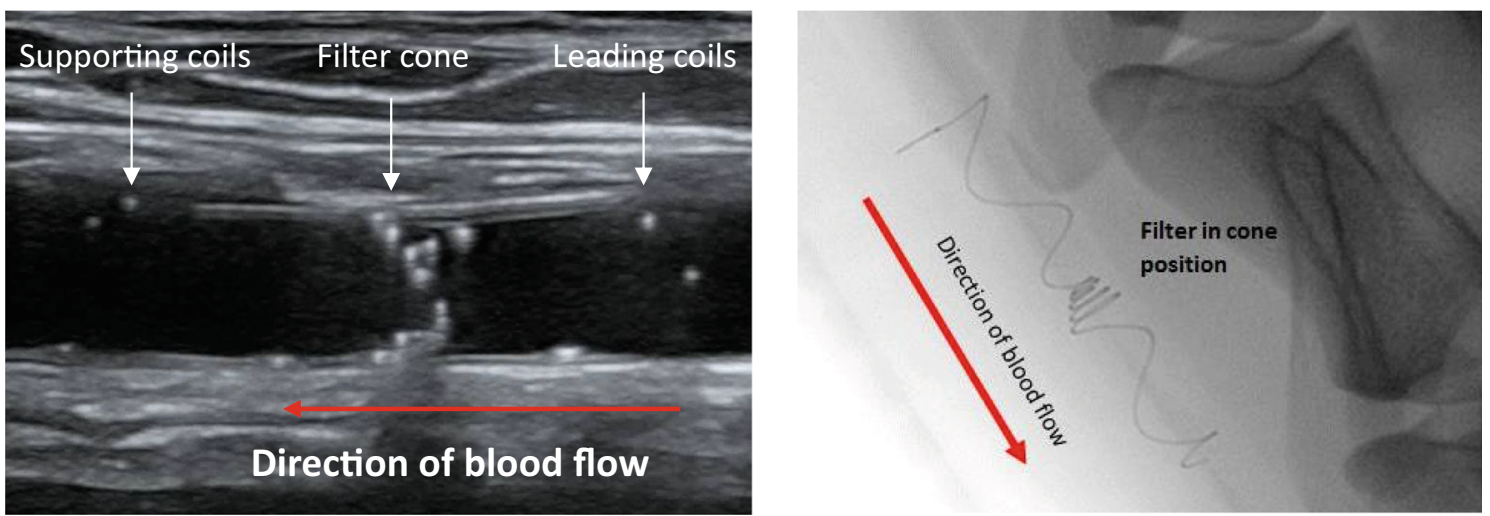

Fig. 5 Ultrasound (left panel) and X-ray (right panel) images of implant

is not straight (zigzag) due to postmortem rigor mortis effect. There was minimal progression of neo-intimal growth over time (no difference between specimens at 1 month and up to 7 months).

The scanning electron microscope (SEM) analysis of all groups ( $n=2$, each) showed a correctly deployed and secured implant with only minimal signs of fibrin and blood cells deposited. No evidence of meaningful thrombus deposition was noted at the implant surface. The endothelial layer did not show abnormalities. Representative SEM pictures are shown in Fig. 7.

\section{Acute Retraction Study}

In this study, implant retraction with the pulling wire ( $n=12$ implants) at $4 \pm 0.5 \mathrm{~h}$ post implantation was achieved without difficulty using ultrasound guidance. This was done on the day of implantation and at day 12 (no vascular complications, no device integrity malfunctions). Gross pathology and histopathology findings at the CCA wall and surrounding tissue were minimal and observed in both retraction and control (puncturing only) sites.

Fig. 6 CCA segments,

histopathology at termination (4,

12 , and 31 weeks, H\&E staining)

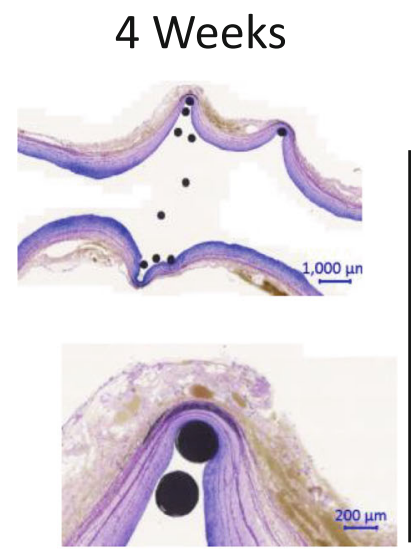

12 Weeks

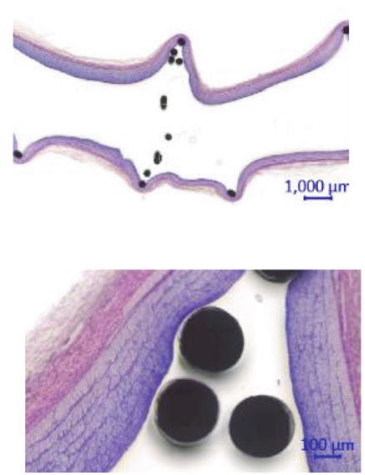

31 Weeks

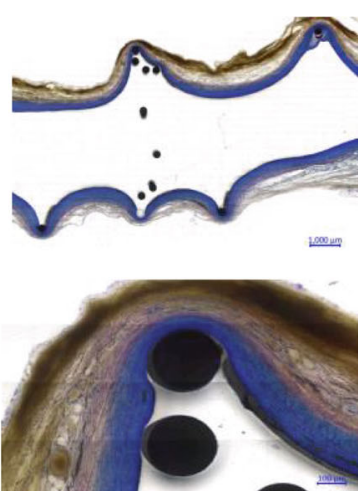



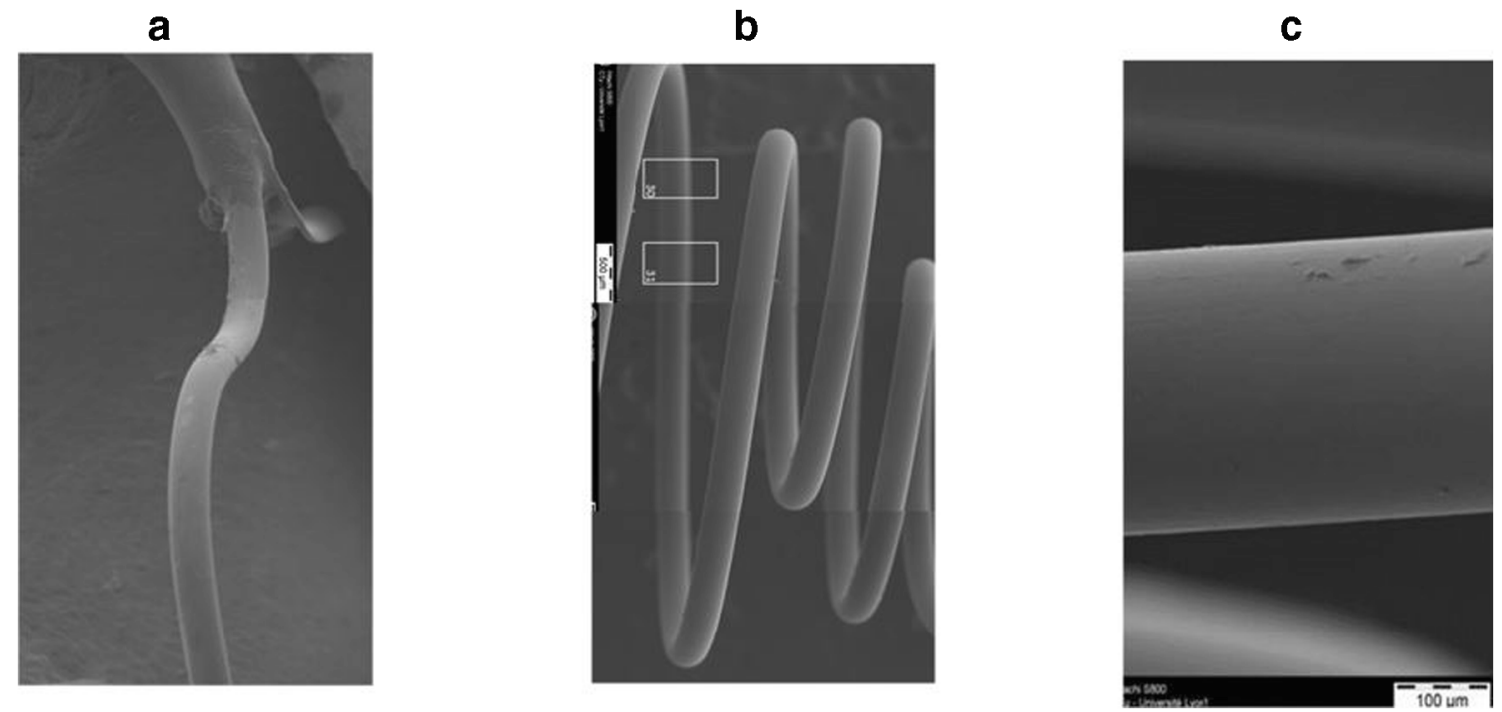

Fig. 7 SEM images at termination (13 weeks): (a) Internal Anchor X40, (b) Filter X40, and (c) Filter Wire X200

follow-up in 10 animals. In 3/10 arteries, thrombus on filter was very large $(>5 \mathrm{~cm})$ at 1 month ( 2 cases) and 2 months (1 case). In these 3 arteries, temporary partial obstruction was observed, and implant shape was distorted. In all 3 arteries, normal blood flow resumed after thrombus regression. At final necropsy, no thrombi remnants were observed in any animal.

\section{Clinical Evaluation}

The safety and effectiveness of the CCA filter system is being evaluated in three separate clinical studies, one completed, one ongoing, and the third planed:

The first in human study (CAPTURE 1, completed) was uncontrolled and included 25 patients with AF, with $\mathrm{CHA}_{2} \mathrm{DS}_{2}$-VASc score $\geq 2$, unsuitable for OAC. Antithrombotic treatment consisted of aspirin + clopidogrel for 3 months, followed by aspirin lifelong.

The safety study, (CAPTURE 2, ongoing) is also uncontrolled and is planned to include 100 patients with $\mathrm{AF}$ and a previous history of ischemic stroke. Patients have a $\mathrm{CHA}_{2} \mathrm{DS}_{2}$-VASc score $\geq 4$ and are receiving OAC (clinicaltrials.gov - NCT03892824). Antithrombotic treatment consists of OAC + clopidogrel + aspirin for 1 month, followed by $\mathrm{OAC}+$ clopidogrel for 5 months, followed by $\mathrm{OAC}$ as prior to implant.

A randomized controlled trial (INTERCEPT, planned to commence in 2021, will include 3500 patients, with $\mathrm{CHA}_{2} \mathrm{DS}_{2}$-VASc score $\geq 3$, receiving OAC. It is a randomized superiority trial that will compare bilateral carotid filter implants to no carotid filter, on top of OAC in all patients, with a primary efficacy endpoint of ischemic stroke. There is no "dummy" procedure planned.

\section{First in Human Clinical Study (CAPTURE 1)}

The first in human study, titled "Carotid Artery Implant for Trapping Upstream Emboli (CAPTURE 1) for Preventing Stroke in Atrial Fibrillation Patients," was designed to assess the safety, feasibility, and tolerability of the system and implantation procedure in AF patients with $\mathrm{CHA}_{2} \mathrm{DS}_{2}$-VASc score $\geq 4$ and deemed unsuitable for oral anticoagulants $(\mathrm{OAC})$. The main exclusion criteria were CCA plaque in the "landing zone" and carotid stenosis $>30 \%$ in CCA, ICA, and ECA. The "landing zone" segment that needed to be free of plaque needed to be $4 \mathrm{~cm}$ in length (considering a $3.5-4 \mathrm{~cm}$ filter length). Study medications included heparin intra-procedure, clopidogrel + aspirin for 3 months, and aspirin lifelong. The study was designed as a multicenter, prospective, nonrandomized, single arm, open-label study. Study outcomes were evaluated by an independent clinical events committee. A total of 48 patients underwent ultrasound screening: 23 patients (47\%) were not enrolled due to either feasibility issues or withdrawal of consent. The remaining 25 patients had mean age of 71.3 years, $16(74 \%)$ were male, and the mean $\mathrm{CHA}_{2} \mathrm{DS}_{2}$-VASc score was 4.4 . Nearly half the patient cohort $(48 \%)$ had a history of stroke, TIA, or thromboembolism.

It was only possible to attempt filter implantation on both sides in $23 / 25$ (92\%) of patients due to poor imaging quality bilaterally ( 1 patient) and to previously unrecognized atheromatous plaque in the CCA on one side (1 patient). In the remaining 23 patients, the overall rate of initial successful deployment on the initial attempt was 47 out of 56 filters (84\%). In the 9 patients with an initially unsuccessful implantation attempt, all devices (100\%) were immediately retracted successfully using the pulling wire, and successful reimplantation was then performed. There were no major adverse events during the procedure. Of the 24 patients receiving 
an implant (23 bilaterally and one unilaterally), 24, 22, and 20 patients completed 3,6 , and 12 months follow-up, respectively ( 3 device-unrelated deaths and 1 patient lost to follow-up). No major device-related adverse events were seen during follow-up. Of the 47 implants (in 24 patients) that were properly positioned by the end of the procedure, all 47 (100\%) remained properly positioned at all subsequent follow-ups. A typical X-ray image of bilateral correct filter positioning post implantation is shown in Fig. 8.

A puncture site skin hematoma occurred in several patients but was apparently related to soft tissue needle trauma, and no peri-CCA hematoma was observed in these cases by ultrasound imaging. In 3 of these cases, there was concomitant neck edema (confirmed by CT scanning), which possibly resulted from local reaction of soft tissue to blood oozing. All cases of hematoma/edema resolved by the 1-month follow-up visit without treatment. Three patients died of causes unrelated to the procedure or the device. One patient had two consecutive minor strokes, adjudicated as procedure/device unrelated, concomitant with unprovoked deep vein thrombosis (DVT). In both instances of stroke, MRI revealed several small infarcts in multiple brain territories including occipital lobes. Ultrasound imaging of that patient's filters did not reveal thrombus on filter or any other abnormal finding.

Routine carotid ultrasound imaging was performed in all patients at 1 day, 1 week, and 1, 3, 6, and 12 months. There were 7 occurrences of asymptomatic thrombi on the filter in 4 patients, occurring between 1 and 9 months. No thrombus caused an interruption to blood flow as assessed by color Doppler ultrasound. Thrombi resolved completely within 0.5-5 months (with low molecular weight heparin in 3 and without in one). In one additional patient, a thrombus first

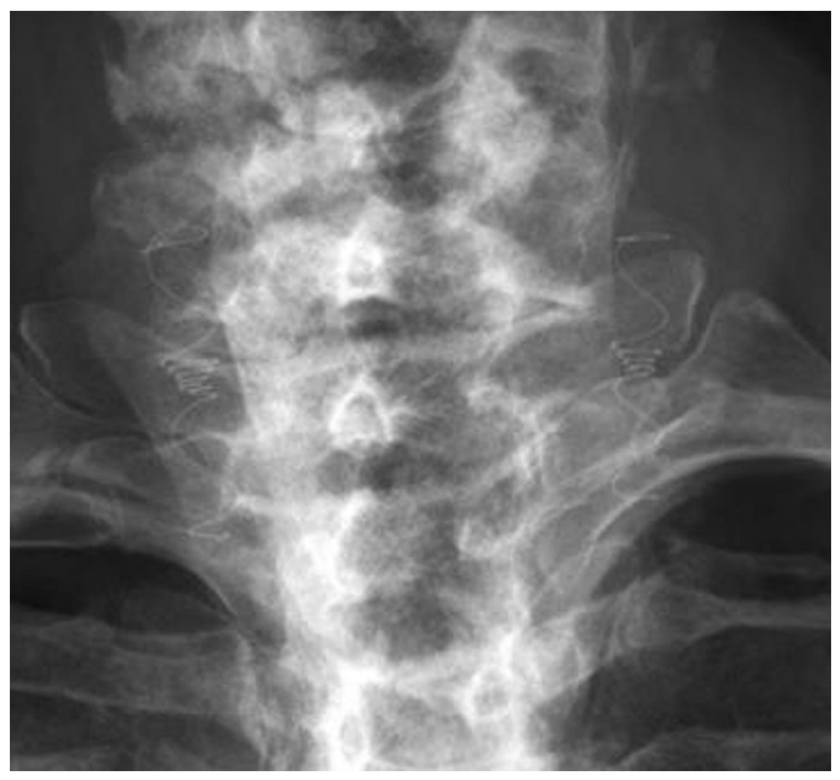

Fig. 8 Vine $^{\mathrm{TM}}$ filters in human CCAs observed at the final follow-up visit at 12 months appears to be regressing during extended follow-up.

\section{Discussion and Conclusions}

Stroke prevention in atrial fibrillation remains an important medical need, despite the introduction of the highly effective non-warfarin oral anticoagulants. Absolute stroke risk remains unacceptably high in patients with AF patients with multiple risk factors (especially prior stroke), even when prescribed anticoagulation. This residual risk of cardio-embolism is partly due to inadequate dosing and to interruptions of anticoagulation for various reasons, including noncompliance and bleeding. Consequently, there is an unmet need for a sizable group of $\mathrm{AF}$ patients to improve stroke prevention. The permanent CCA filter is designed to provide protection additive to anticoagulation against anterior circulation stroke in such patients - who represent the vast majority of disabling strokes in patients with AF.

The relative success of the left atrial appendage occlusion device supports the concept of intravascular exclusion of embolism, but the left atrial occlusion device has several limitations compared with the vascular filter. It cannot exclude embolism coming from sources other than the left atrium, and implantation requires a major endovascular procedure with multi-disciplinary team and multiple imaging modalities to implant [37••, 38]. In addition, this device has not been tested as an adjunct to ongoing anticoagulation in high-risk AF patients [39].

In vitro and in vivo studies showed that the CCA filter captured thromboemboli which in turn completely resolved in time (weeks to months) and with no distal pieces observed in the manifold. This suggests that the risk of downstream embolization is low. The minimal neo-intimal growth is likely related to the relatively low radial force exerted by the implant on the carotid wall ( $\sim 5$ to $10 \%$ oversized relative to the CCA systolic diameter) as compared with carotid stents (30-100\% oversized). The CCA filter is fixed in place by extra- and intraluminal anchors; accordingly, migration is completely eliminated irrespective of the low radial force. The device can be readily implanted and retrieved (with pulling wire) and surgically extracted if necessary.

In a small study in patients with $\mathrm{AF}$, device implantation and long-term follow-up was achieved with a high degree of safety. Ongoing and planned future studies will further define the safety and efficacy of this device for its intended use. The initial human study results indicate that deployment of a permanent coil filter in the human CCA is feasible and reasonably safe. The only potentially serious adverse effect was stroke, but the clinical picture suggested that this was not caused by the device. There were $4 / 25$ patients in whom thrombus was detected on the implanted filters by routine 
ultrasound at various times during follow-up ( 7 cases), all occurring without stroke symptoms. In 6 cases, routine ultrasound imaging showed gradual but complete regression of thrombus over several months. In the 7 th case, in which thrombus was detected late during follow-up (12 months), regression appears to be ongoing. Thrombus regressed while receiving sub-cutaneous heparin in 6 cases, and without in one case. It is not possible to know if thrombus detected on a filter is a "captured embolus" or an "in situ thrombus" formed on the filter. However, there are some clues that suggest that these were captured emboli. What was observed in sheep after injection of thrombus proximal to the filter was capture of these emboli by the filter, and these filter-associated thrombi had a string-like appearance. This is in contrast to the echogenic bulky mass appearance of in situ thrombus which formed on the filter in sheep immediately following implantation. The thrombi seen in patients had an appearance very similar to the string-like appearance of captured emboli in sheep, suggesting an embolic source. As observed in the sheep with captured emboli, we documented thrombus regression in all patients, presumably due to thrombolysis and the high shear force within the arterial circulation.

We observed a low procedural risk which is consistent with the evidence that inadvertent carotid artery puncture during jugular vein access rarely causes significant sequelae and that CCA punctures with needles smaller than $18 \mathrm{G}$ are benign [40-42]. The risk of inadvertent plaque rupture during carotid puncture was further mitigated by excluding atheromatous CCA segments using ultrasound screening. To reduce hematoma formation, we have introduced more meticulous application of local pressure at the puncture site for several minutes following implantation.

In summary, we have made significant progress in the development of a new device-based treatment for stroke prevention in AF. It is designed to be deployed easily with a high index of safety, and it is being developed as complementary to pharmacological treatment (rather than as an alternative) for higher risk AF patients. Extensive preclinical, as well as early human experience, suggests that the CCA filter could become a new devicebased additive treatment for stroke prevention in AF. Ongoing and planned clinical trials are needed to further evaluate the efficacy and safety of this personalized preventive approach.

\section{Compliance with Ethical Standards}

Conflict of Interest Tom De Potter reports non-financial support from Javelin Medical.

Ofer Yodfat, Guy Shinar, and Avraham Neta report a grant from Israel Innovation Authority, they are employees of Javelin Medical, and they have licensed patents $(10226321,6387343,9220588,10028819$, 6370312, 9592110).

Vivek Y. Reddy reports stock options in Javelin Medical and DinovaHangzhou Nuomao Medtech Co, Ltd. and equity in Surecor. He also reports grant support from Abbott, Boston Scientific and Biosense
Webster. He has relationships with other medical companies: Ablacon (Consultant, Equity), Acutus Medical (Consultant, Equity), Affera, (Consultant, Equity), Apama Medical (Consultant, Equity), Aquaheart (Consultant, Equity), Atacor (Consultant, Equity), Autonomix (Consultant, Equity), Axon (Consultant), Backbeat (Consultant, Equity), BioSig (Consultant, Equity), Biotronik, (Consultant), Cardiofocus (Consultant), Cardionomic (Consultant), CardioNXT/ AFTx (Consultant), Circa Scientific, (Consultant, Equity), Corvia Medical (Consultant, Equity), East End Medical (Consultant, Equity), EBR (Consultant), EPD (Consultant, Equity), Epix Therapeutics (Consultant, Equity), EpiEP (Consultant, Equity), Eximo (Consultant, Equity), Farapulse (Consultant, Equity), Fire1 (Consultant, Equity), Impulse Dynamics (Consultant), Javelin (Consultant, Equity), Kardium (Consultant, Equity), Keystone Heart (Consultant, Equity), LuxCath (Consultant, Equity), Manual Surgical Sciences (Equity), Medlumics (Consultant, Equity), Medtronic (Consultant), Middlepeak (Consultant, Equity), Newpace (Equity), Nuvera (Consultant, Equity), Philips (Consultant), Sirona Medical (Consultant, Equity), Stimda (Consultant), Thermedical (Consultant),

Valcare (Consultant, Equity), and Vizaramed (Equity).

Petr Neuzil reports no conflicts of interest.

Roland Veltkamp reports personal fees from Javelin, grants and personal fees from Bayer, grants from Boehringer, grants and personal fees from BMS, grants and personal fees from Pfizer, grants from Daiichi Sankyo, and grants from Biogen.

Stuart J. Connolly reports personal fees from Javelin.

Human and Animal Rights and Informed Consent Informed consent was obtained from all individual participants included in the human studies. Human and animal studies were performed in accordance with the declaration of Helsinki. Human and animal studies were performed according to the good clinical practice and good laboratory practice guidelines, where appropriate.

Open Access This article is licensed under a Creative Commons Attribution 4.0 International License, which permits use, sharing, adaptation, distribution and reproduction in any medium or format, as long as you give appropriate credit to the original author(s) and the source, provide a link to the Creative Commons licence, and indicate if changes were made. The images or other third party material in this article are included in the article's Creative Commons licence, unless indicated otherwise in a credit line to the material. If material is not included in the article's Creative Commons licence and your intended use is not permitted by statutory regulation or exceeds the permitted use, you will need to obtain permission directly from the copyright holder. To view a copy of this licence, visit http://creativecommons.org/licenses/by/4.0/.

\section{References}

Papers of particular interest, published recently, have been highlighted as:

- Of importance

•• Of major importance

1. Colilla S, Crow A, Petkun W, Singer DE, Simon T, Liu X. Estimates of current and future incidence and prevalence of atrial fibrillation in the US adult population. Am J Cardiol. 2013;112(8): 1142-7.

2. Benjamin EJ, Virani SS, Callaway CW, American Heart Association Council on Epidemiology and Prevention Statistics Committee and Stroke Statistics Subcommittee, et al. Heart 
Disease and Stroke Statistics - 2018 Update: a report from the American Heart Association. Circulation. 2018;137(12):e67-e492.

3. Yiin GSC, Li L, Bejot Y, Rothwell PM. Time trends in atrial fibrillation-associated stroke and premorbid anticoagulation. Stroke. 2019;50(1):21-7.

4. Lip GY. The $\mathrm{CHA}_{2} \mathrm{DS}_{2}-\mathrm{VASc}$ score for stroke risk stratification in patients with atrial fibrillation: a brief history. Eur Heart J. 2015;36(42):2880-5.

5. Friberg L, Skeppholm M, Terént A, et al. Benefit of anticoagulation unlikely in patients with atrial fibrillation and a $\mathrm{CHA}_{2} \mathrm{DS}_{2}-\mathrm{VASc}$ score of 1. J Am Coll Cardiol. 2015;65:225-32.

6. Hart RG, Pearce LA, Rothbart RM, McAnulty JH, Asinger RW, Halperin JL. Stroke with intermittent atrial fibrillation: incidence and predictors during aspirin therapy. J Am Coll Cardiol. 2000;35:183-7.

7. Wolf PA, Abbott RD, Kannel WB. Atrial fibrillation as an independent risk factor for stroke: the Framingham Study. Stroke. 1991;22: 983-8.

8. Vanassche T, Lauw MN, Eikelboom JW, et al. Risk of ischemic stroke according to pattern of atrial fibrillation: analysis of 6563 aspirin-treated patients in ACTIVE-A and AVERROES. Eur Heart J. 2014;36:281-8.

9. Hart RG, Pearce LA, Aguilar MI. Meta-analysis: antithrombotic therapy to prevent stroke in patients who have non-valvular atrial fibrillation. Ann Intern Med. 2007;146(12):857-67.

10. Seiffge DJ, De Marchis GM, Koga M, et al. RAF, RAF-DOAC, CROMIS-2, SAMURAI, NOACISP, Erlangen, and Verona registry collaborators. Ann Neurol. 2020. This large pooled analysis of 7 prospective studies identifies patients with stroke under anticoagulation at clear elevated risk of new recurrent stroke despite continued treatment with anticoagulation.

11. Xian Y, Xu H, O'Brien EC, et al. Clinical effectiveness of direct oral anticoagulants vs warfarin in older patients with atrial fibrillation and ischemic stroke: findings from the patient-centered research into outcomes stroke patients prefer and effectiveness research (PROSPER) study. JAMA Neurol. 2019;22.

12. Seiffge DJ, Paciaroni M, Wilson D, Koga M, Macha K, Cappellari $\mathrm{M}$, et al. (CROMIS-2, RAF, RAF-DOAC, SAMURAI, NOACISP LONGTERM, Erlangen, and Verona registry collaborators). Direct oral anticoagulants versus vitamin $\mathrm{K}$ antagonists after recent ischemic stroke in patients with atrial fibrillation. Ann Neurol. 2019;85(6):823-34.

13. Diener HC, Eikelboom J, Connolly SJ, Joyner CD, Hart RG, Lip $\mathrm{GY}$, et al. Apixaban versus aspirin in patients with atrial fibrillation and previous stroke or transient ischemic attack: a predefined subgroup analysis from AVERROES, a randomized trial. Lancet Neurol. 2012;11:225-31.

14. Easton JD, Lopes RD, Bahit MC, Wojdyla DM, Granger CB, Wallentin L, et al. Apixaban compared with warfarin in patients with atrial fibrillation and previous stroke or transient ischaemic attack: a subgroup analysis of the ARISTOTLE trial. Lancet Neurol. 2012;11:503-11.

15. Hankey GJ, Patel MR, Stevens SR, Becker RC, Breithardt G, Carolei A, et al. Rivaroxaban compared with warfarin in patients with atrial fibrillation and previous stroke or transient ischemic attack: a subgroup analysis of ROCKET AF. Lancet Neurol. 2012;11:315-22.

16. Diener HC, Halperin JL, Fox K, Hankey GJ. Stroke prevention with rivaroxaban in higher risk populations with atrial fibrillation. Int $\mathrm{J}$ Clin Pract. 2015;69(7):743-56.

17. Cavallari I, Ruff CT, Nordio F, et al. Clinical events after interruption of anticoagulation in patients with atrial fibrillation: an analysis from the ENGAGE AF-TIMI 48 trial. Int J Cardiol. 2018;257:102_ 7.

18. Yao X, Abraham NS, Alexander GC, et al. Effect of adherence to oral anticoagulants on risk of stroke and major bleeding among patients with atrial fibrillation. J Am Heart Assoc. 2016;5(2): e003074.

19. Patel MR, Vellkamp AS, Lokhnygina Y, et al. Outcomes of discontinuing rivaroxaban compared with warfarin in patients with nonvalvular atrial fibrillation: analysis from the ROCKET AF trial (rivaroxaban once-daily, oral, direct factor Xa inhibition compared with vitamin $\mathrm{K}$ antagonism for prevention of stroke and embolism trial in atrial fibrillation). J Am Coll Cardiol. 2013;61(6):651-8.

20. Ghoshal NG. Ruminant heart and arteries. In: Getty R, editor. Sisson \& Grossman's Anatomy of the Domestic Animals. 5th ed: W. B. Saunders; 1975. p. 1005-11.

21. Fisher CM. Capsular infarcts - the underlying vascular lesions. Arch Neurol. 1979;36:65-73.

22. Di Carlo A, Lamassa M, Baldereschi M, European BIOMED Study of Stroke Care Group, et al. Risk factors and outcome of subtypes of ischemic stroke - data from a multicenter multinational hospitalbased registry. The European Community Stroke Project. J Neurol Sci. 2006;244(1-2):143-50.

23. Rai AT, Hogg JP, Cline B, Hobbs G. Cerebrovascular geometry in the anterior circulation: an analysis of diameter, length, and the vessel taper. J Neurointerv Surg. 2013;5(4):371-5.

24. Chung EM, Hague JP, Chanrion MA, et al. Embolus trajectory through a physical replica of the major cerebral arteries. Stroke. 2010;41(4):647-52.

25. Türe U, Yaşargil MG, Al-Mefty O, et al. Arteries of the insula. J Neurosurg. 2000;92(4):676-87.

26. Müller HR, Brunhölzl C, Radü EW, et al. Sex and side differences of cerebral arterial caliber. Neuroradiology. 1991;33(3):212-6.

27. Han J, Qiao H, Li X, Li X, He Q, Wang Y, et al. The threedimensional shape analysis of the M1 segment of the middle cerebral artery using MRA at 3T. Neuroradiology. 2014;56(11):9951005.

28. Vuillier F, Medeiros E, Moulin T, Cattin F, Bonneville JF, Tatu L. Main anatomical features of the M1 segment of the middle cerebral artery: a 3D time-of-flight magnetic resonance angiography at 3T study. Surg Radiol Anat. 2008;30(6):509-14.

29. Muller-Hulsbeck S, et al. In vitro comparison of four cerebral protection filters for preventing human plaque embolization during carotid interventions. J Endovasc Ther. 2002;9:793-802.

30. Siewiorek GM, Wholey MH, Finol EA. In vitro performance assessment of distal protection filters: pulsatile flow conditions. J Endovasc Ther. 2009;16:735-43.

31. Scheel P, Ruge C, Schöning M. Flow velocity and flow volume measurements in the extracranial carotid and vertebral arteries in healthy adults: reference data and the effects of age. Ultrasound Med Biol. 2000;26(8):1261-6.

32. Foley SR, Solano C, Simonova G, Spanevello MM, Bird RJ, Semple JW, et al. A comprehensive study of ovine haemostasis to assess suitability to model human coagulation. Thromb Res. 2014; 134(2):468-73.

33. Connell JM, Khalapyan T, Al-Mondhiry HA, et al. Anticoagulation of juvenile sheep and goats with heparin, warfarin, and clopidogrel. ASAIO J. 2007;53(2):229-37.

34. Mottaghy K, Oedekoven B, Poppel K, et al. Heparin free long-term extracorporeal circulation using bioactive surfaces. ASAIO Trans. 1989;35(3):635-7.

35. Berny PJ, de Oliveira LA, Videmann B, Rossi S. Assessment of ruminal degradation, oral bioavailability, and toxic effects of anticoagulant rodenticides in sheep. Am J Vet Res. 2006;67(2):363-71.

36. Boos AM, Ringwald J, Mieth M, et al. New aspects on efficient anticoagulation and antiplatelet strategies in sheep. BMC Vet Res. 2013;9:192-219.

37.• Reddy VY, Sievert H, Halperin J, et al. PROTECT AF Steering Committee and Investigators. Percutaneous left atrial appendage closure vs. warfarin for atrial fibrillation: a randomized clinical trial. JAMA. 2014;312(19):1988-98. This randomized trial showed 
noninferiority of a mechanical stroke prevention strategy (LAA closure in this trial) to anticoagulation for the first time.

38. Holmes DR Jr, Doshi SK, Kar S, Price MJ, Sanchez JM, Sievert H, et al. Left atrial appendage closure as an alternative to warfarin for stroke prevention in atrial fibrillation: a patient-level meta-analysis. J Am Coll Cardiol. 2015;65(24):2614-23.

39. January CT, Wann LS, Calkins H, Chen LY, Cigarroa JE, Cleveland JC Jr, et al. 2019 AHA/ACC/HRS Focused Update of the 2014 AHA/ACC/HRS Guideline for the management of patients with atrial fibrillation: a report of the American College of Cardiology/American Heart Association Task Force on Clinical Practice Guidelines and the Heart Rhythm Society. J Am Coll Cardiol. 2019;74(1):104-32.
40. Ruesch $\mathrm{S}$, Walder $\mathrm{B}$, Tramèr MR. Complications of central venous catheters: internal jugular versus subclavian access-a systematic review. Crit Care Med. 2002;30(2):454-60.

41. Shah KB, Rao TL, Laughlin S, El-Etr AA. A review of pulmonary artery catheterization in 6,245 patients. Anesthesiology. 1984;61(3):271-5.

42. Yilmazlar A, Bilgin H, Korfali G, Eren A, Özkan U. Complications of 1303 central venous cannulations. J R Soc Med. 1997;90(6): 319-21.

Publisher's Note Springer Nature remains neutral with regard to jurisdictional claims in published maps and institutional affiliations. 